\title{
Response to comment on "Identification of substances with potential for long-range transport as possible substances of very high concern"
}

\author{
Christiane Zarfl • Ines Hotopp • Nils Kehrein • \\ Michael Matthies
}

Received: 24 April 2013 /Accepted: 29 April 2013 /Published online: 17 May 2013

(C) Springer-Verlag Berlin Heidelberg 2013

In his comment on our article "Identification of substances with potential for long-range transport as possible substances of very high concern" [1], Sierra Rayne identified several substances, which might lead to another classification as indicated by us. We agree with Dr. Rayne that one substance ethanol, 2,2',2"-nitrilotris-, compound with (chlorometyl)oxirane (1:1) (CAS No. 68141-08-02) is significantly ionized in most aquatic systems. He further claimed that some compounds have been classified as persistent although they are rapidly hydrolyzed. We clearly described in the methods section of our article that we used the fugacity module of the EPI Suite for estimating degradation half-lives in air, water, sediment, and soil (p. 3154). The latter three half-lives are determined using the BIOWIN estimation program. "If a compound is susceptible to abiotic hydrolysis under environmental conditions, ... then the user must manually enter the value into the Fugacity, Half-life
Selection option." (EPI Suite, fugacity help file). We developed an automatic screening procedure for a large substance list without manually entered values and evaluated "the screening results for the identified 11 compounds...to underline that estimated parameters of the technically identified substances can be confirmed..." (p. 3159). We thank Dr. Rayne for checking the substances on their hydrolytic degradation potential, which is very helpful to prioritizing chemicals as possible substances of very high concern.

\section{References}

Zarfl C, Hotopp I, Kehrein N, Matthies M (2012) Identification of substances with potential for long-range transport as possible substances of very high concern. Environ Sci Pollut Res 19:3152-3161

Responsible editor: Leif Kronberg

C. Zarfl $\cdot$ I. Hotopp $\cdot$ N. Kehrein $\cdot$ M. Matthies Institute of Environmental Systems Research, University

of Osnabrück, Osnabrück, Germany

C. Zarfl $(\bowtie)$

Leibniz-Institute of Freshwater Ecology and Inland Fisheries,

Berlin, Germany

e-mail: zarfl@igb-berlin.de 